\title{
Using Yellow Rocket as a Trap Crop for Diamondback Moth (Lepidoptera: Plutellidae)
}

\author{
FRANCISCO R. BADENES-PEREZ, ANTHONY M. SHELTON, AND BRIAN A. NAULT
}

Department of Entomology, Cornell University, New York State Agricultural Experiment Station, 630 W. North Street, Geneva, NY 14456

\section{J. Econ. Entomol. 98(3): 884-890 (2005)}

\begin{abstract}
Yellow rocket, Barbarea vulgaris (R. Br.) variety arcuata, was evaluated as a trap crop for diamondback moth, Plutella xylostella (L.) (Lepidoptera: Plutellidae), in cabbage, Brassica oleracea L. variety capitata, in 2003 and 2004. In 2003, the numbers of P. xylostella larvae found in field plots of cabbage alone were 5.2-11.3 times higher than those on cabbage plants in plots that included cabbage and several rows of yellow rocket. In an outdoor experiment in screenhouses, P. xylostella oviposition on cabbage was compared among six treatments that varied in the percentage of yellow rocket in relation to cabbage $(0,4,8,16,24$, and $32 \%$ of the plants were yellow rocket). Results indicated that the percentage of eggs laid on cabbage decreased as the percentage of yellow rocket in the treatment increased, but this decrease was not significant beyond $20 \%$ of the plants being yellow rocket. In 2004, the numbers of $P$. xylostella larvae in field plots of cabbage alone were $1.6-2.4$ and 1.7-2.8 times higher than numbers in treatments with 10 and $20 \%$ trap crop, respectively. Sticky trap and sweep net captures of $P$. xylostella adults indicated that within-field dispersal was reduced by the presence of yellow rocket and aggregation occurred around yellow rocket plants. Our study suggests that using yellow rocket as a trap crop may reduce $P$. xylostella infestations in cabbage fields, and this possibility is discussed in the context of general crop and insect pest management practices in crucifers.
\end{abstract}

KEY WORDS Plutella xylostella, Barbarea vulgaris, trap crop, management

The DiAmondBack MOTH, Plutella xylostella (L.) (Lepidoptera: Plutellidae), is considered the most damaging insect pest of cruciferous crops throughout the world (Talekar 1992). The facility of P. xylostella to develop resistance to insecticides (Tabashnik et al. 1990, Shelton et al. 1993, Zhao et al. 2002), combined with general environmental and health concerns, has stimulated interest in developing alternative management techniques such as trap crops (Talekar and Shelton 1993, Hooks and Johnson 2003). Trap crops, especially Indian mustard, Brassica juncea (L.) Czern, and collards, Brassica oleracea L. variety acephalla, have been evaluated for control of P. xylostella over the past decade (Hooks and Johnson 2003). Yet, conclusions based on using these trap crop hosts to manage $P$. xylostella have been contradictory, proclaiming them as successful (Srinivasan and Krishna Moorthy 1992, Mitchell et al. 2000, Åsman 2002), unsuccessful (Silva-Krott et al. 1995, Luther et al. 1996, Bender et al. 1999, Shelton and Nault 2004), or unreliable (Musser et al. 2005).

Another trap crop suggested for $P$. xylostella control is yellow rocket, Barbarea vulgaris (R. Br.) variety arcuata (Idris and Grafius 1994, 1996; Badenes-Perez et al. 2004; Lu et al. 2004; Shelton and Nault 2004), a biannual invasive weed that occurs in temperate regions worldwide (MacDonald and Cavers 1991, Uva et al. 1997). Despite showing good potential as a trap crop, yellow rocket has never been tested in the field. A major reason for this lack of field testing is that yellow rocket is considered a noxious weed, thus farmers might be reluctant to adopt it as a trap crop. However, the biannual cycle of yellow rocket greatly diminishes the chances of it seeding and accumulating in the seed bank, as long as it is removed at the end of the crop season. Furthermore, among several potential trap crops examined, the G-type yellow rocket (with glabrous glossy leaves) showed greater potential as a trap crop than collards and Indian mustard because it was both highly attractive for P. xylostella oviposition, and larvae did not survive on it (BadenesPerez et al. 2004).

An important factor to consider in trap cropping is the most effective spatial arrangement of the trap crop in relation to the main crop. It is essential to understand the behavior of the insect pest, particularly its within-field movement patterns, in the presence of the trap crop (Hokkanen 1991, Banks and Ekbom 1999, Potting et al. 2005). A trap crop that, in addition to being preferred over the main crop, elicits an aggregation and arrestment response in the insect pest would be desirable. For example, if the trap crop was planted along the perimeter of the main crop, it would intercept the insect arriving to the field and mitigate 
colonization of the main crop. An arrestment effect in adult activity was not consistently observed in $P$. $x y$ lostella when using glossy collards as a trap crop (Musser et al. 2005); however, other plants may be more effective in eliciting arrestment. Multiple-choice experiments have shown that yellow rocket was more attractive to P. xylostella than glossy collards (Badenes-Perez et al. 2004), which could result in significant P. xylostella arrestment if yellow rocket were used as a trap crop.

Planting a noncrop as a trap crop requires land to be sacrificed at the expense of the main crop. Therefore, the minimum amount of land devoted to a trap crop that is sufficient to reduce the target pest population is desired. Most general guidelines for trap cropping recommend that $\approx 10 \%$ of the total crop area be planted with the trap crop (Hokkanen 1991); however, the actual needs for each particular system may vary and have to be determined specifically.

The main objectives of this study were to examine in the field the possibility of using yellow rocket as a trap crop for P. xylostella and to estimate the minimum percentage of yellow rocket plants necessary to make it effective as a trap crop. Additionally, we wanted to determine whether $P$. xylostella adults were more likely to show aggregation and arrestment on yellow rocket than on cabbage plants.

\section{Materials and Methods}

Experiments were conducted at the New York State Agricultural Experiment Station in Geneva, NY. P. xylostella used in all experiments originated from populations collected in cabbage fields in Camilla, GA, and Donna, TX, in 2003 and 2004, respectively. After collection from the field, P. xylostella colonies were maintained in the laboratory on a wheat germ-casein artificial diet (Shelton et al. 1991). Insects were released in the experimental arenas in a 1:1 sex ratio. 'Bobcat' cabbage (Reed's Seeds, Cortland, NY) and G-type yellow rocket were used in our experiments. Yellow rocket seeds were obtained from wild plants growing near Ithaca, NY. All plants used in the experiments were initially grown using Cornell mix (one part peat moss: two parts vermiculite) in $15-\mathrm{cm}$ pots in the greenhouse and later moved outdoors for at least 2 wk before beginning experiments. All plants used in this study were $12 \mathrm{wk}$ old at the time they were transplanted into the field or moved to screenhouses, and they did not flower at the time they were used in the experiments (both cabbage and yellow rocket are biennial). During the time before experimentation, plants were fertilized weekly with an all-purpose 15-30-15 fertilizer (Wilson Laboratories Inc., Springdale, CT).

Field Experiment I (2003). The purpose of this experiment was to evaluate yellow rocket as a trap crop for P. xylostella in the field, as well as to compare within-field movement of $P$. xylostella in the absence and presence of yellow rocket.

Plants were transplanted in the soil in a field at the Cornell's Fruit and Vegetable Crops Research Farm in
Geneva on 18 June 2003, when they were 12 wk old Plants were transplanted in rows separated by $0.9 \mathrm{~m}$ with $0.45-\mathrm{m}$ spacing between adjacent plants within rows. Field plots were conventionally tilled, and fertilizer and herbicide were applied according to current recommendations (Reiners et al. 2003). In both 2003 and 2004, before the beginning of the experiment, natural infestations of $P$. xylostella in the field were very low $(<0.1$ larvae per plant $)$ and to reduce them further, $\approx 1$ wk before each release, plots were sprayed with either spinosad (SpinTor 2 SC, $0.1 \mathrm{~kg}[\mathrm{AI}] / \mathrm{ha}$, Dow AgroSciences LLC, Indianapolis, IN) or Bacillus thuringiensis variety kurstaki (DiPel Pro DF, $1.0 \mathrm{~kg}$ $[\mathrm{AI}] /$ ha, Valent BioSciences Corporation, Libertyville, IL).

Plots had 14 rows with 18 plants each. A treatment with a solid planting of cabbage was compared with a treatment with $28 \%$ yellow rocket, in which rows 1,2 , 13 , and 14 were planted with yellow rocket, whereas the remainder was cabbage. Each plot was surrounded by $3.5 \mathrm{~m}$ of bare soil and two rows of 'Seneca Indian' corn (Johnny's Seeds, Albion, ME) to provide a physical barrier for minimizing insect movement between plots. A randomized complete block design was used to arrange six plots for each treatment. P. xylostella adults were released at a rate of 0.5 per host plant (126 total) from a plastic container placed on the west side of each plot $0.5 \mathrm{~m}$ outside the middle of the first yellow rocket row, simulating the arrival of moths to the field from one side of the field. To ensure a high and temporarily predictable $P$. xylostella infestation, two releases of moths were made (8 July and 11 August). Approximately $2 \mathrm{wk}$ after the first and second release, P. xylostella larvae were recorded as third and fourth instars by randomly inspecting five plants in rows 4,6 , 9 , and 11 of each plot (a total of 20 cabbage plants, $8 \%$ of the total plants in the plot, were examined in each plot).

During the second release, adult and egg densities of P. xylostella also were recorded to assess within-field movement. Adults were monitored using sticky traps made with inverted 473-ml white Styrofoam drinking cups (base diameter, $5.5 \mathrm{~cm}$; opening diameter, $9 \mathrm{~cm}$; height, $14 \mathrm{~cm}$ ) mounted with a white plastic ring (outside diameter, $14 \mathrm{~cm}$; i.d., $8.5 \mathrm{~cm}$ ). The plastic ring provided the sticky trap with a lip around its lower base, which gave the trap a hat-like shape. This design improved adult moth capture by trapping adults that dropped onto the lip after flying into the side of the cup. The design of these traps was based on a previously described model for monitoring P. xylostella adults (Mo et al. 2001). The outside of the cup and the upper side of the plastic ring were coated with Tangle-Trap Insect Trap Coating (Tanglefoot Company, Grand Rapids, MI). Sticky traps were placed on fiberglass stakes with a 10 by $10-\mathrm{cm}$ wooden platform that could be adjusted with a clip to place the bottom of the trap $\approx 5 \mathrm{~cm}$ above the canopy of the cabbage plants. Two sticky traps were placed in the middle of rows 5 and 10. Sticky traps were inspected 2 and $4 \mathrm{~d}$ after releasing adults, and the cumulative number of 

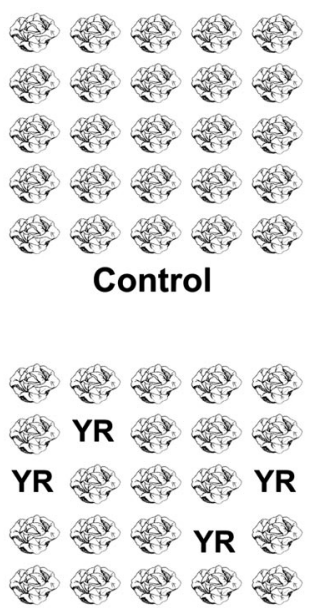

16\% Yellow Rocket
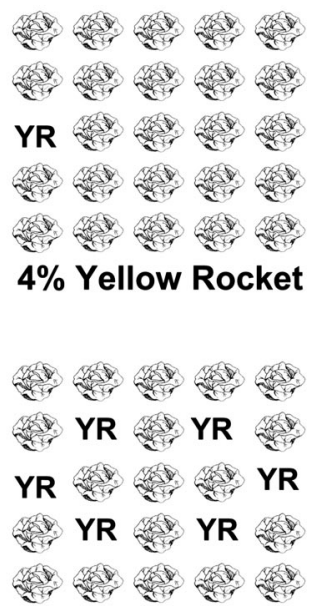

24\% Yellow Rocket

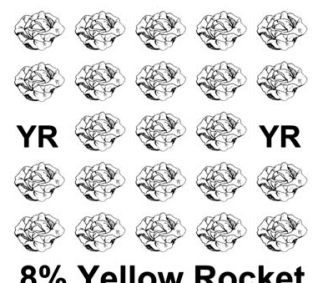

8\% Yellow Rocket

Fig. 1. Diagram of treatments conducted in screenhouses to test the effect of increasing the percentage of yellow rocket plants in relation to cabbage on P. xylostella oviposition on cabbage.

P. xylostella adults per trap was recorded. Data from the two traps were pooled for each plot.

Egg densities were determined by randomly collecting five plants in rows 2 (1.6 m from the release point) and 13 (11.5 m from the release point) $4 \mathrm{~d}$ after releasing the moths. The number of $P$. xylostella eggs per plant was recorded in the laboratory by using a dissecting microscope.

Screenhouse Experiment (2003). This experiment was conducted to determine the relationship between percentage of yellow rocket in a cabbage-yellow rocket mixture and numbers of eggs laid on cabbage. Results from this experiment were used to determine the range of treatments evaluated in the field experiment in 2004.

Plants were moved to outdoor screenhouses on 16 June 2003 ( $24 \mathrm{~h}$ before experimentation), when they were 12 wk old. Screenhouses were $3.2 \mathrm{~m}$ in width by $4.7 \mathrm{~m}$ in length by $2.5 \mathrm{~m}$ in height. There were six treatments containing a mix of yellow rocket and cabbage plants $(0,4,8,16,24$, and $32 \%$ of yellow rocket), and all treatments included a total of 25 plants (Fig. 1). For all replicates, yellow rocket plants were located in the same position, and adjacent plants were separated $0.6 \mathrm{~m}$ from each other. Adults of P. xylostella $<2 \mathrm{~d}$ old were released at a rate of 1.5 per plant (38 total) from a plastic container placed on top of a wooden platform ( $80 \mathrm{~cm}$ above ground) in the middle of the screenhouse. A 50-ml Erlenmeyer flask with a 10\% sugar solution and dental wick (Absorbal, Wheat Ridge, $\mathrm{CO}$ ) was placed at the release point to provide a food source for moths. Two days after releasing the moths, the number of eggs on each plant was counted in the laboratory by using a dissecting microscope. Treatments were randomly assigned to screenhouses and treatments were replicated three times. Multiple screenhouses were used, each of which was considered a replicate or block.

Field Experiment II (2004). The purpose of this experiment was to compare P. xylostella infestations among four percentages of yellow rocket. Additionally, $P$. xylostella adults were sampled on cabbage and yellow rocket plants to compare the level of aggregation on both hosts.

Cultural and experimental practices in this experiment were similar to those used to evaluate yellow rocket as a trap crop in the field in 2003. However, plots in this experiment had 10 rows with 20 plants each. All plants were transplanted into soil in the field on 15 June 2004, when they were 12 wk old. A treatment with a solid planting of cabbage was compared with treatments with 5,10 , and $20 \%$ yellow rocket. In the treatment with $5 \%$ yellow rocket, one of every three plants was yellow rocket in rows 1 and 10, and the remaining plants were cabbage; in the treatment with $10 \%$ yellow rocket, every other plant in rows 1 and 10 was yellow rocket plant, and the remaining plants were cabbage; and in the treatment with $20 \%$ yellow rocket, all plants in rows 1 and 10 were yellow rocket plants, and the remaining plants were cabbage. Each plot was surrounded by $7 \mathrm{~m}$ of bare soil and separated from adjacent plots by four (east-west) or 12 (north-south) rows of Roundup Ready corn (Monsanto Company, St. Louis, MO) to minimize insect movement between adjacent plots. The four treatments were arranged in a randomized complete block design, and blocks were replicated four times (total of 16 plots). Adults of P. xylostella were released on 2 July and 1 August at a rate of 0.5 per plant (100 total) from a plastic container placed on the east and west sides of each plot, $0.5 \mathrm{~m}$ outside the middle of the two opposite border rows. Approximately $2 \mathrm{wk}$ after each release, larvae of $P$. xylostella were recorded as third and fourth instars by randomly inspecting five plants in rows 2,4 , $5,6,7$, and 9 of each plot (a total of 30 cabbage plants, $15 \%$ of the total plants in the plot, were examined in each plot).

The number of $P$. xylostella adults resting on yellow rocket and cabbage plants was determined $4 \mathrm{~d}$ after the second release by covering individual plants with 


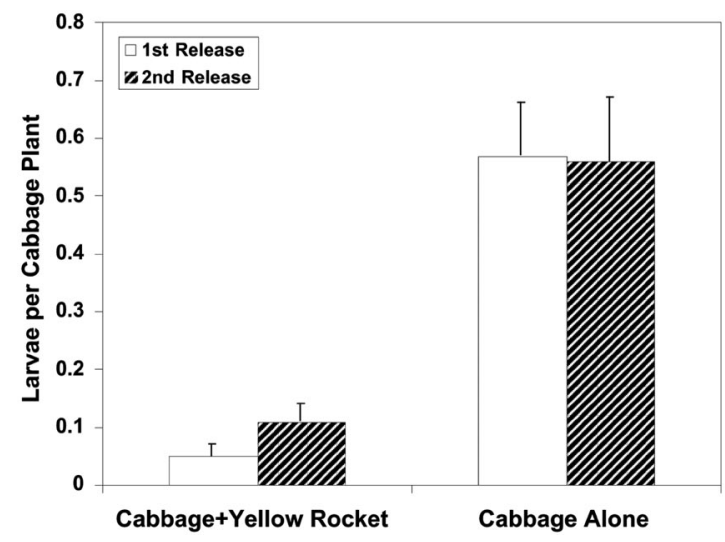

Fig. 2. Mean ( \pm SEM) P. xylostella larvae in treatments with only cabbage and a mixture of cabbage and yellow rocket, such that $28 \%$ of the planting consisted of yellow rocket (2003).

a sweep net and shaking them to dislodge P. xylostella adults present on the plant. A total of five randomly selected plants on the two opposite outer rows (rows 1 and 10) of the treatments with cabbage alone and $20 \%$ yellow rocket were used for this purpose (10 plants for each treatment replicate).

Statistical Analyses. For the data in the screenhouse experiment, a nonlinear model was used to identify the minimum percentage of yellow rocket needed for this trap crop to be most effective. Data from the percentage of eggs laid on cabbage were analyzed by using nonlinear segmented regression analysis with the PROC NLIN procedure of SAS (SAS Institute 2004). Treatments in both field experiments were analyzed using analysis of variance (ANOVA) with the PROC GLM procedure of SAS (SAS Institute 2004). Because the blocking term was not significant in the analyses for the field experiments, this term was removed to increase the error degrees of freedom from 5 to 10 . When significant treatment differences were indicated by a significant F-test at $P \leq 0.05$, means were separated by Fisher's protected least significant difference (LSD) (SAS Institute 2004). To normalize the residuals, before analysis data were transformed using a natural $\log (x+1)$ function. Although all tests of significance were based on the transformed data, only untransformed data are presented.

\section{Results}

Field Experiment I (2003). Larval infestations of P. xylostella on cabbage were significantly lower in the treatment with yellow rocket than in the treatment with cabbage alone for both the first $(F=46.85$; $\mathrm{df}=$ $1,10 ; P<0.001)$ and the second release $(F=19.65$; $\mathrm{df}=1,10 ; P=0.001$ ) (Fig. 2). On average, cabbage plants in the treatment with cabbage alone had 11.3 and 5.2 more larvae than cabbage plants in the treatment with the trap crop for the first and second release, respectively.

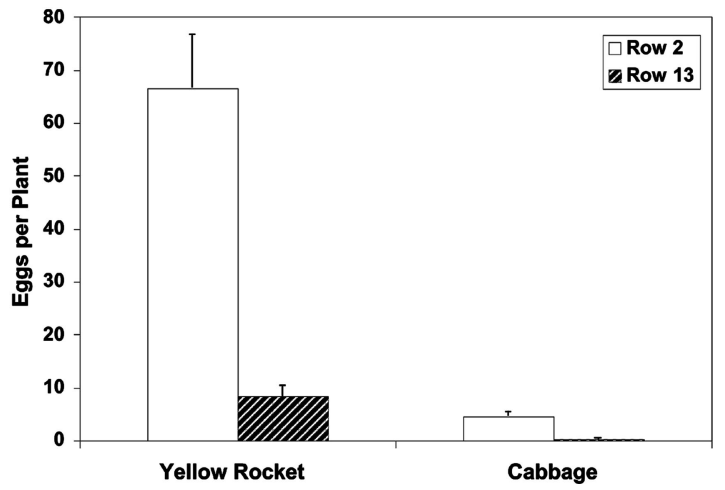

Fig. 3. Mean ( \pm SEM) P. xylostella eggs in rows 2 and 13 of treatments within cabbage only plots those containing $28 \%$ yellow rocket plants in a mixture of cabbage and yellow rocket (2003).

In the treatment with yellow rocket, 8.0 times more eggs were laid on the yellow rocket plants on row 2 (closer to the release point) than on yellow rocket plants on row $13(F=58.98 ; \mathrm{df}=1,10 ; P<0.001)$ (Fig. 3). Similarly, in the treatment with cabbage alone, 20.4 times more eggs were laid on plants in row 2 than on row $13(F=83.88 ; \mathrm{df}=1,10 ; P<0.001)$. In both treatments, $P$. xylostella laid significantly more eggs closer to the release point. When comparing the treatment with yellow rocket and the treatment with cabbage alone, 14.2 and 20.3 times more eggs were laid on the yellow rocket than on the cabbage plants for rows $2(F=146.10 ; \mathrm{df}=1,10 ; P<0.001)$ and $13(F=$ $65.82 ; \mathrm{df}=1,10 ; P<0.001$ ), respectively, indicating that the trap crop was significantly more attractive to P. xylostella than cabbage.

Significantly more P. xylostella adults were captured on sticky traps in the cabbage-alone treatment than on the treatment with yellow rocket $2 \mathrm{~d}(F=17.93 ; \mathrm{df}=$ $1,10 ; P=0.002)$ and $4 \mathrm{~d}(F=5.88 ; \mathrm{df}=1,10 ; P=0.035)$ after insect release (Fig. 4). The number of $P$. xylostella adults caught was 6.0 and 2.5 times higher in the treatment with cabbage alone than in the treatment with a yellow rocket trap crop for the first and second release, respectively. These results suggest that with-

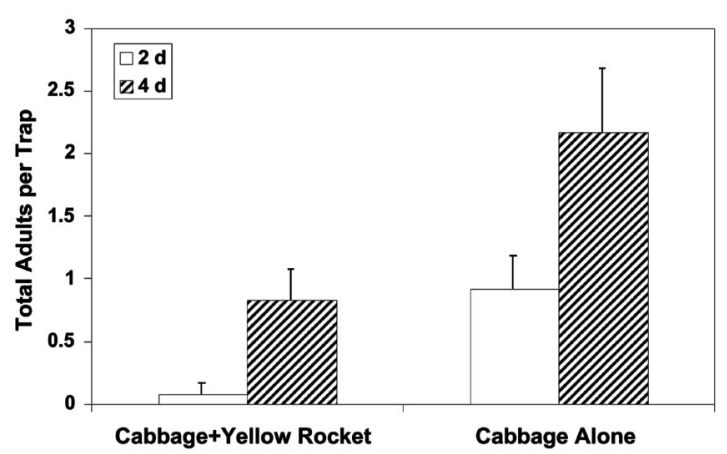

Fig. 4. Mean ( \pm SEM) P. xylostella adults caught in sticky traps located in rows 5 and 10 of treatments with only cabbage and $28 \%$ yellow rocket (2003). 


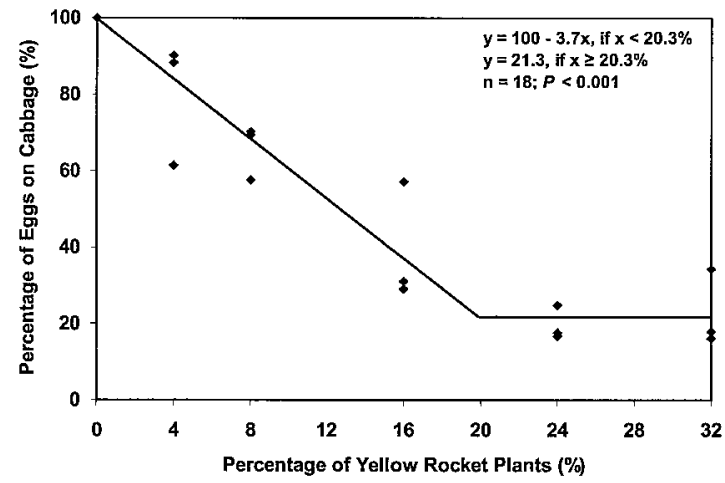

Fig. 5. Mean ( \pm SEM) P. xylostella oviposition in screenhouses with increasing percentages of yellow rocket in a mixture of cabbage and yellow rocket.

in-field movement was minimized by the presence of yellow rocket as a trap crop.

Screenhouse Experiment (2003). A nonlinear segmented model represented by the equations $\mathrm{y}=\mathrm{a}+$ $b(x-t)$, if $x<t$ and $y=b$, if $x \geq t$, was used to determine the percentage of yellow rocket $(y)$ after which there was not a significant reduction in the percentage of eggs laid on cabbage $(x)$. The estimated parameters and respective standard errors were as follows: $\mathrm{a}=21.3 \pm 3.9, \mathrm{~b}=3.7 \pm 0.5$, and $\mathrm{t}=20.3 \pm$ $2.1(\mathrm{y}=21.3-3.7(\mathrm{x}-20.3)$, if $\mathrm{x}<20.3 \%, \mathrm{y}=21.3$, if $\mathrm{x} \geq 20.3 \% ; n=18$; MSE $=94.3 ; P<0.001$ ) (Fig. 5). This model showed that the percentage of eggs laid on cabbage decreased as the percentage of yellow rocket in the mixture increased; however, this decrease was not significant after the percentage of yellow rocket in the treatment exceeded $20.3 \%$. This percentage (20\%) was used as the maximum percentage tested in the 2004 field experiment.

Field Experiment II (2004). Differences in P. xylostella larval infestations existed among treatments during both the first $(F=4.96 ; \mathrm{df}=3,12 ; P=0.018)$ and the second release $(F=3.98 ; \mathrm{df}=3,12 ; P=0.035)$ (Fig. 6). Larval densities were 2.4 and 2.8 times higher on the cabbage plants without the trap crop than on those with the 10 and $20 \%$ trap crop during the first release and 1.6 and 1.7 times higher during the second release, respectively. For both releases, larval densities in the $5 \%$ yellow rocket treatment were significantly higher than those in the treatment with $20 \%$ yellow rocket. Larval densities in the treatment with cabbage alone were significantly greater than larval densities in the treatments with 10 and $20 \%$ yellow rocket but were similar to the $5 \%$ yellow rocket treatment, indicating that the minimum percentage of yellow rocket necessary to reduce P. xylostella infestations was between 5 and $10 \%$.

In the border rows, 4.7 times more $P$. xylostella adults were caught on yellow rocket plants (treatment with $20 \%$ yellow rocket) than on cabbage plants (treatment with cabbage alone) $(F=205.99 ; \mathrm{df}=1$, $6 ; P<0.001$ ) (Fig. 7). These results suggest that P. xylostella adults tended to aggregate on yellow rocket plants.

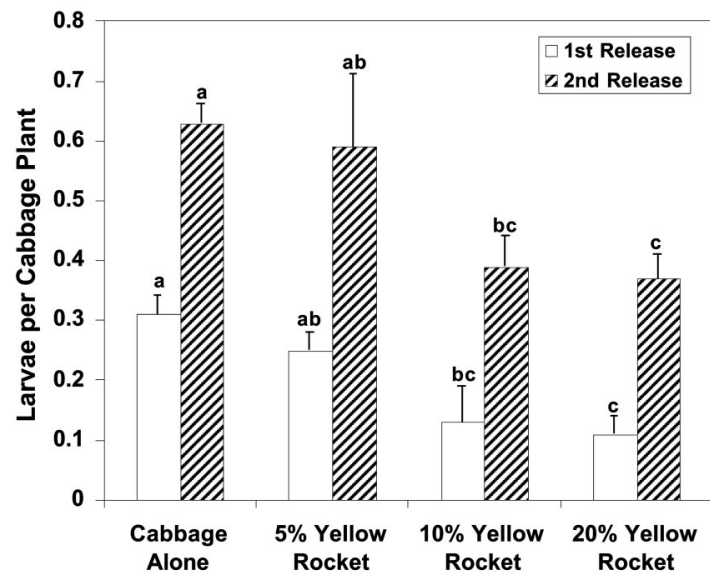

Fig. 6. Mean ( \pm SEM) P. xylostella larvae in treatments with only cabbage and 5,10 , and $20 \%$ yellow rocket (2004). Within each release, different letters above the bars denote significant differences between treatments, $P \leq 0.05$ (Fisher's protected LSD, SAS Institute 2004)

\section{Discussion}

Yellow rocket can reduce $P$. xylostella infestations when used as a trap crop in cabbage fields. As indicated in previous studies modeling the effect of trap crops on densities of the target insect pest populations (Banks and Ekbom 1999, Hannunen 2005, Potting et al. 2005), densities of P. xylostella decreased with increasing percentages of trap crop cover. In our study, planting $10 \%$ of a field with yellow rocket was sufficient to significantly reduce $P$. xylostella populations.

$P$. xylostella oviposition was greater closer to the point of release than at further distances. This observation is in agreement with other studies that reported P. xylostella aggregation around release points (Caprio and Tabashnik 1992) and limited movement within crop fields (Mo et al. 2001). Within-field movement of P. xylostella adults in the presence of yellow rocket was decreased and aggregation on yellow rocket plants increased compared with movement and aggregation in plots with cabbage alone. These findings suggest

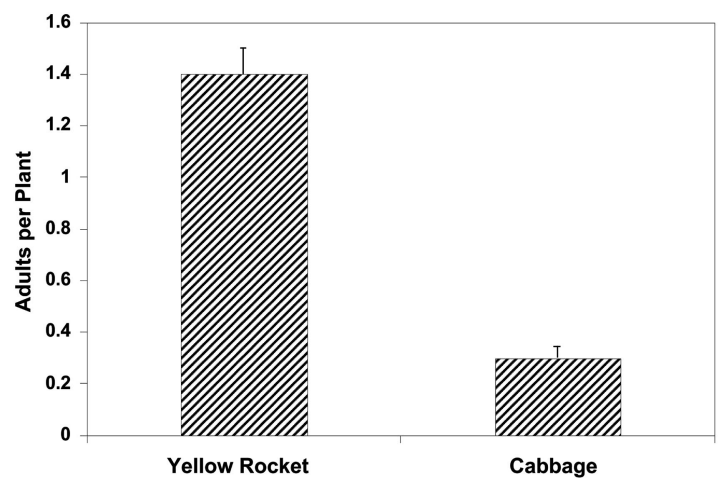

Fig. 7. Mean ( \pm SEM) P. xylostella adults found on either cabbage or yellow rocket plants on border rows of treatments with only cabbage and $20 \%$ yellow rocket (2004). 
that a perimeter trap crop would intercept $P$. xylostella adults moving into the field from the edge and may limit their dispersal into the main crop. However, even at the highest percentages of yellow rocket, $P$. xylostella laid some eggs on the main crop, indicating that total arrestment by the trap crop did not occur. It is not clear to what extent subsequent generations of P. xylostella would be reduced by yellow rocket in the plots.

Spatial scale is also an important factor in herbivore response to vegetation heterogeneity (Banks 1998) and behavior of $P$. xylostella may be different in larger fields (e.g., commercial fields in New York state are larger than the size of our field plots). Furthermore, in fields with a low perimeter/area ratio, or when P. xylostella densities are high, a perimeter trap crop may require more yellow rocket to be planted within the field. Additional trap crop plants could either be planted in strips or mixed randomly within the field. Although dispersal of P. xylostella within a uniform host patch seems to be random and nondirectional (Mo et al. 2001), it is unknown whether movement of P. xylostella adult females in a patch with hosts of different attractiveness is based on random movement and local attraction, which would imply a trap crop mixed randomly as the best spatial arrangement, or whether it is based on attraction to the highest concentration of the preferred host, implying that planting strips of the trap crop would be more effective. Previous studies with P. xylostella and other insects indicate that the maximum distance over which insects can orient toward host plant volatile chemicals in the field is only a few meters (Städler 1992, Finch and Collier 2000), suggesting that perhaps a trap crop mixed randomly within the main crop may increase the chances of $P$. xylostella encountering the trap crop. However, this may not be the best approach if the main crop has to be harvested mechanically and separately from the trap crop.

Yellow rocket can only work as a trap crop for a limited number of insect pests. Besides its potential as a trap crop for P. xylostella, the high attractiveness of yellow rocket to the flea beetles Phyllotreta cruciferae Goeze and Phyllotreta striolata (F.) suggests that it also could be used as a trap crop for these species (Root and Tahvanainen 1969). Yellow rocket also has been shown to be resistant to larvae of the mustard white butterfly, Pieris napi oleracea (Harris) (Renwick 2002) and the flea beetle Phyllotreta nemorum L. (Agerbirk et al. 2001). In contrast, imported cabbageworm, Pieris rapae (L.) (F.R.B.-P., unpublished data), and black cutworm, Agrotis ipsilon Hufnagel (Busching and Turpin 1977), are able to develop and pupate successfully on yellow rocket. In addition to P. rapae, other important insect pests of crucifers, such as the cabbage looper, Trichoplusia ni (Hübner), and the saltmarsh caterpillar, Estigmene acrea (Drury), cannot be managed in a cabbage field by using yellow rocket as a trap crop (F.R.B.-P., unpublished data). In practice, the convenience of using a broad spectrum insecticide spray to control the entire insect pest complex would be strongly favored over the use of yellow rocket, which would primarily control $P$. xylostella Furthermore, the loss of profits derived from allocating a percentage of the crop area to a plant that cannot be marketed will also decrease the feasibility of adoption of this strategy. Yet, in those cases where P. xylostella is the key pest, where it has developed resistance to available insecticides, or where insecticides may not be accessible, such as in developing countries, the use of yellow rocket as a trap crop for P. xylostella may be practical.

Given the slower growth pattern and smaller size of yellow rocket than cabbage, yellow rocket seeds would need to be planted 2 or $3 \mathrm{wk}$ before cabbage to allow seedlings to be transplanted simultaneously. Furthermore, older plants and higher planting densities have been shown to increase the attractiveness of yellow rocket to P. xylostella (Badenes-Perez et al. 2005). Integrating these cultural practices could reduce the need of trap crop area, but further studies are needed to test this hypothesis.

\section{Acknowledgments}

We thank Jan Nyrop for helpful suggestions and Hilda Collins for rearing the insects used in our experiments. Thanks to Mary Lou Hessney, Hanna Hoffman, Shirley Lewis, Eric Smith, Evan Van Gorder, Fred Musser, Katie Straight, and Mabel Tomas for field and laboratory assistance. We also thank John Barnard for assistance with statistical analyses. Funding for this study was provided by National Science Foundation Center for Integrated Pest Management (Subcontract 1900-0006-07) and the USDA Pest Management Alternative Program (Grant 2001-34381-11153).

\section{References Cited}

Agerbirk, N., C. E. Olsen, and J. K. Nielsen. 2001. Seasonal variation in leaf glucosinolates and insect resistance in two types of B. vulgaris ssp. arcuata. Phytochemistry 58: $91-100$.

Åsman, K. 2002. Trap cropping effect on oviposition behaviour of the leek moth Acrololepsis assectella and the diamondback moth Plutella xylostella. Entomol. Exp. Appl. 105: 153-164.

Badenes-Perez, F. R., A. M. Shelton, and B. A. Nault. 2004. Evaluating trap crops for diamondback moth, Plutella xylostella (Lepidoptera: Plutellidae). J. Econ. Entomol. 97: 1365-1372.

Badenes-Perez, F. R., B. A. Nault, and A. M. Shelton. 2005. Manipulating the attractiveness and suitability of hosts for diamondback moth (Lepidoptera: Plutellidae). J. Econ. Entomol. 98: 836-844.

Banks, J. E. 1998. The scale of landscape fragmentation affects herbivore response to vegetation heterogeneity. Oecologia (Berl.) 117: 239-246.

Banks, J. E., and B. Ekbom. 1999. Modelling herbivore movement and colonization: pest management potential of intercropping and trap cropping. Agric. For. Entomol. 1: 165-170.

Bender, D. A., W. P. Morrison, and J. R. Kern. 1999. Intercropping cabbage and Indian mustard for potential control of lepidopterous and other insects. HortScience 34: 275-279.

Busching, M. K., and F. T. Turpin. 1977. Survival and development of black cutworm (Agrotis ipsilon) larvae on 
various species of crop plants and weeds. Environ. Entomol. 6: 63-65.

Caprio, M. A., and B. E. Tabashnik. 1992. Allozymes used to estimate gene flow among populations of diamondback moth (Lepidoptera: Plutellidae) in Hawaii. Environ. Entomol. 21: 806-816.

Finch, S., and R. H. Collier. 2000. Host-plant selection by insects - a theory based on 'appropriate/inappropriate landings' by pest insects of cruciferous plants. Entomol. Exp. Appl. 96: 91-102.

Hannunen, S. 2005. Modelling the interplay between pest movement and the physical design of trap crop systems. Agric. For. Entomol. 7: 11-20.

Hokkanen, H.M.T. 1991. Trap cropping in pest management. Annu. Rev. Entomol. 36: 119-138.

Hooks, C.R.R., and M. W. Johnson. 2003. Impact of agricultural diversification on the insect community of cruciferous crops. Crop Prot. 22: 223-238.

Idris, A. B., and E. Grafius. 1994. The potential of using Barbarea vulgaris in insecticide-resistant diamondback moth management. Resistance Pest Manage. Newsl. 6: $7-8$.

Idris, A. B., and E. Grafius. 1996. Effects of wild and cultivated host plants on oviposition, survival, and development of diamondback moth (Lepidoptera: Plutellidae) and its parasitoid Diadegma insulare (Hymenoptera: Ichneumonidae). Environ. Entomol. 25: 825-833.

Lu, J., Y. B. Liu, and A. M. Shelton. 2004. Laboratory evaluations of a wild crucifer Barbarea vulgaris as a management tool for diamondback moth. Bull. Entomol. Res. 94: $509-516$.

Luther, G. C., H. R. Valenzuela, and J. Defrank. 1996. Impact of cruciferous trap crops on lepidopteran pests of cabbage in Hawaii. J. Econ. Entomol. 25: 39-47.

MacDonald, M. A., and P. B. Cavers. 1991. The biology of Canadian weeds. 97. Barbarea vulgaris R. Br. Can. J. Plant Sci. 71: 149-166.

Mitchell, E. R., G. Y. Hu, and D. Johanowicz. 2000. Management of diamondback moth (Lepidoptera: Plutellidae) in cabbage using collard as a trap crop. HortScience 35: 875-879.

Mo, J., G. Baker, M. Keller, and R. Roush. 2001. Local dispersal of the diamondback moth (Plutella xylostella $(\mathrm{L}$.) (Lepidoptera: Plutellidae). Environ. Entomol. 32: 71-79.

Musser, F. R., B. A. Nault, J. P. Nyrop, and A. M. Shelton. 2005. Impact of a glossy collard trap crop on diamondback moth (Lepidoptera: Plutellidae) adult movement, oviposition and larval survival. Entomol. Exp. Appl. (in press)

Potting, R.P.J., J. N. Perry, and W. Powell. 2005. Insect behavioural ecology and other factors affecting the control efficacy of agro-ecosystem diversification strategies. Ecol. Model. 182: 199-216.

Reiners, S., C. H. Petzhold, and M. P. Hoffmann [eds.]. 2003. 2003 Integrated crop and pest management guidelines for commercial vegetable production. Cornell Cooperative Extension, Ithaca, NY.
Renwick, J.A.A. 2002. The chemical world of crucivores: lures, treats and traps. Entomol. Exp. Appl. 104: 35-42.

Root, R. B., and J. O. Tahvanainen. 1969. Role of winter cress, Barbarea vulgaris, as a temporal host in the seasonal development of the crucifer fauna. Ann. Entomol. Soc. Am. 62: 852-855.

SAS Institute. 2004. SAS/STAT user's guide, version 9.1 SAS Institute, Cary, NC.

Shelton, A. M., and B. A. Nault. 2004. Dead-end trap cropping: a technique to improve management of the diamondback moth, Plutella xylostella (Lepidoptera: Plutellidae). Crop Prot. 23: 497-503.

Shelton, A. M., R. J. Cooley, M. K. Kroening, W. T. Wilsey, and S. D. Eigenbrode. 1991. Comparative analysis of two rearing procedures for diamondback moth (Lepidoptera: Plutellidae). J. Entomol. Sci. 26: 17-26.

Shelton, A. M., J. A. Wyman, N. L. Cushing, K. Apfelbeck, T. J. Dennehy, S.E.R. Mahr, and S. D. Eigenbrode. 1993. Insecticide resistance of diamondback moth (Lepidoptera: Plutellidae) in North America. J. Econ. Entomol. 86 $11-19$.

Silva-Krott, I. U., P. Singh, T. S. Lali, and R. Muniappan. 1995. Development of a trap cropping system for cabbage in Guam. Pest Manage. Hortic. Ecosyst. 1: 27-35.

Srinivasan, K., and P. N. Krishna Moorthy. 1992. The development and adoption of integrated pest management for major pests of cabbage using Indian mustard as a trap crop, pp. 511-521. In N. Talekar [ed.], 2nd International Workshop on the Diamondback Moth and other Cruciferous Pests. Asian Vegetable Research and Development Center, Taipei, Taiwan.

Städler, E. 1992. Behavioral responses of insects to plant secondary compounds, pp. 45-88. In M. Berenbaum [ed.], Herbivores, their interactions with secondary plant metabolites. Academic, New York.

Tabashnik, B. E., N. L. Cushing, and M. W. Johnson. 1990. Field development of resistance to Bacillus thuringiensis in diamondback moth (Lepidoptera: Plutellidae). J. Econ. Entomol. 83: 1651-1676.

Talekar, N. S. 1992. Management of diamondback moth and other crucifer pests: Proceedings of the second international workshop. In N. Talekar [ed.]. Asian Vegetable Research and Development Center, Shanhua, Taiwan.

Talekar, N. S., and A. M. Shelton. 1993. Biology, ecology, and management of the diamondback moth. Annu. Rev. Entomol. 38: 275-301.

Uva, R. H., J. C. Neal, and J. M. DiTomaso. 1997. Weeds of the northeast. Cornell University Press, Ithaca, NY.

Zhao, J. Z., Y. X. Li, H. L. Collins, L. Gusukuma-Minuto, R.F.L. Mau, G. D. Thompson, and A. M. Shelton. 2002. Monitoring and characterization of diamondback moth (Lepidoptera: Plutellidae) resistance to spinosad. J. Econ. Entomol. 95: 430-436.

Received 5 November 2004; accepted 14 March 2005. 